OPEN ACCESS

Approved by:

Frontiers Editorial Office,

Frontiers Media SA, Switzerland

${ }^{*}$ Correspondence: Houqing Long

longhq@mail.sysu.edu.cn; houqinglong@163.com

†These authors share first authorship

Specialty section This article was submitted to

Neurodegeneration,

a section of the journal

Frontiers in Neuroscience

Received: 08 February 2021 Accepted: 09 February 2021 Published: 25 February 2021

Citation:

Cheng X, YU Z, XU J, Quan D and Long $H$ (2021) Corrigendum: Pathophysiological Changes and the

Role of Notch-1 Activation After Decompression in a Compressive Spinal Cord Injury Rat Model.

Front. Neurosci. 15:665669. doi: 10.3389/fnins.2021.665669

\section{Corrigendum: Pathophysiological Changes and the Role of Notch-1 Activation After Decompression in a Compressive Spinal Cord Injury Rat Model}

\author{
Xing Cheng ${ }^{1 \dagger}$, Zhengran Yu ${ }^{1 \dagger}$, Jinghui $X u^{1}$, Daping Quan ${ }^{2}$ and Houqing Long ${ }^{1 *}$ \\ ${ }^{1}$ Guangdong Provincial Key Laboratory of Orthopaedics and Traumatology, Orthopaedic Research Institute/Department of \\ Spine Surgery, The First Affiliated Hospital, Sun Yat-sen University, Guangzhou, China, ${ }^{2}$ PCFM Lab, GD HPPC Lab, School \\ of Materials Science and Engineering, Sun Yat-sen University, Guangzhou, China
}

Keywords: decompression, $\mathrm{CSCl}$, motor function, pathophysiological changes, Notch-1

\section{A Corrigendum on}

Pathophysiological Changes and the Role of Notch-1 Activation After Decompression in a Compressive Spinal Cord Injury Rat Model

by Cheng, X., Yu, Z., Xu, J., Quan, D., and Long, H. (2021). Front. Neurosci. 15:579431. doi: 10.3389/fnins.2021.579431

In the published article, there was an error in affiliation "1". Instead of "Department of Spine Surgery, The First Affiliated Hospital, Sun Yat-sen University, Guangzhou, China”, it should be "Guangdong Provincial Key Laboratory of Orthopaedics and Traumatology, Orthopaedic Research Institute/Department of Spine Surgery, The First Affiliated Hospital, Sun Yat-sen University, Guangzhou, China".

The authors apologize for this error and state that this does not change the scientific conclusions of the article in any way. The original article has been updated.

Copyright () 2021 Cheng, Yu, Xu, Quan and Long. This is an open-access article distributed under the terms of the Creative Commons Attribution License (CC BY). The use, distribution or reproduction in other forums is permitted, provided the original author(s) and the copyright owner(s) are credited and that the original publication in this journal is cited, in accordance with accepted academic practice. No use, distribution or reproduction is permitted which does not comply with these terms. 